\title{
Study of dynamics of lactate dehydrogenase and hepatic enzymes activity following perinatal asphyxia in full term neonates
}

\author{
Deepthi Ramu ${ }^{1}$, Prashanth Madapura V ${ }^{2}$, Sarala Sabapathy ${ }^{3}$, Nidhi Rajendra ${ }^{4}$ \\ ${ }^{1}$ Dr Deepthi Ramu, M.D. Pediatrics, FIPM (Neonatology), \#238, $1^{\text {st }}$ Main, MES Road, Bandappa Nagar, Gokula Post, \\ Bangalore- 560054, India, ${ }^{2}$ Dr Prashanth Madapura.V. MD (Ped), FIPM (Neonatology), Assistant Professor, Department \\ of Pediatrics, M S Ramaiah Medical College and Hospital, MSRIT Post, MSR Nagar, Bangalore-560054, India, \\ ${ }^{3}$ Dr Sarala Sabapathy, M.D. Pediatrics, Professor, Department of Pediatrics, Bangalore Medical College and Research \\ Institute. Bangalore, ${ }^{4}$ Dr Nidhi Rajendra, MD (Path), Consultant Pathologist, Department of Pathology, B R Ambedkar \\ Medical College, KG Halli, Bangalore, India.
}

Address for Correspondence: Dr Prashanth Madapura.V, Email: mvprashanth65@gmail.com

\begin{abstract}
Background and Objectives: Perinatal asphyxia contributes to 1.2 million neonatal deaths each year and is also associated with severe neurodevelopmental disabilities. The aim was to study the dynamics of lactate dehydrogenase, Aspartate Transaminase and Alanine Transaminase following perinatal asphyxia and correlation between the mean levels in different stages of Hypoxic Ischaemic Encephalopathy (HIE) and associated mortality. Methodology: This is a prospective case control study of 210 term neonates, of which 158 neonates with perinatal asphyxia (who required resuscitation in the form of PPV) and 52 in the control group (normal neonates who were delivered in the hospital with no morbidities) were included. After taking the informed written consent from the parents, the relevant information from the history and physical examination were recorded in a predesigned proforma. Venous blood sample was collected at less than 12 hours and at 72 hours after the birth for estimation of LDH, AST and ALT and analysed using ANOVA, Fischer Exact test. Babies were followed up till completed 2 months of age. Results: Incidence of hypoxic hepatitis in the present study is $62.65 \%$ with a significantly high mortality in this group. A significant difference $(\mathrm{P}<0.001)$ was noted between the mean enzyme values of LDH, AST and ALT in all the three stages of HIE and also in levels in between non survivors and survivors. ALT has high specificity and LDH with the highest sensitivity. Conclusion: There seems to be a correlation between serum levels of hepatic enzymes (LDH, ALT and AST) and the extent of CNS injury in Hypoxic Ischaemic Encephalopathy.
\end{abstract}

Keywords: Aspartate Transaminase, Alanine Transaminase, Hepatic Enzymes, Hypoxic Ischaemic Encephalopathy, Lactate Dehydrogenase.

\section{Introduction}

Of the 130 million newborn infants born each year globally, about 4 million die in the neonatal period [1]. According to the World Health Organization (WHO), between four and nine million newborns develop birth asphyxia each year. Of those, an estimated 1.2 million die and at least the same number develop severe consequences, such as epilepsy, cerebral palsy and developmental delay [2]. It is estimated that around $23 \%$ of all newborn deaths are caused by birth asphyxia, with a large proportion of stillbirths [3]. One of the major difficulties in collecting accurate

Manuscript received: $10^{\text {th }}$ August 2016

Reviewed: $24^{\text {th }}$ August 2016

Author Corrected; $7^{\text {th }}$ September 2016

Accepted for Publication: $20^{\text {th }}$ September 2016 epidemiological data on birth asphyxia is the lack of a standard definition of the condition.

Apgar scores at 1 and 5 minutes' correlate poorly with either cause or outcome. Studies conducted so far have relied on indicators with low specificity and poor predictive power for death or neurologic damage, such as low Apgar score or delayed/absent respiration at birth [4].

The defense mechanisms when a fetus is exposed to hypoxia-ischemia is based on ability to centralize cardiac output to prioritized organs such as the brain, heart and the adrenals at the expense of less important 
organs such as the liver, lungs, skin and muscles. Multiorgan dysfunction is a natural consequence of this defense mechanism because of the cellular damage inflicted on the non-prioritized organs. Severe birth asphyxia frequently induces multiorgan failure with cardiovascular, renal, cerebral and hepatic damage [5, $6,7,8]$. Leakage of intracellular enzymes such as aspartate aminotransferase (AST), alanine aminotransferase (ALT) and lactate dehydrogenase (LDH) signaling hepatic dysfunction is seen together with hypoxic ischemic encephalopathy (HIE) after perinatal asphyxia $[9,10,11]$, hence they may be used as potential predictors of timing and grade of the hypoxic ischemic injury in both the perinatal period and in infants with antepartum asphyxia [12-22].

Studies have established that in neonates, these indices may be affected by factors such as viral infections, hepatotoxic agents and metabolic disorders, hence these neonates have been excluded. [8]

Aims and objectives of the study: To study the dynamics of serum hepatic enzyme levels [Lactate dehydrogenase (LDH), Aspartate Transaminase (AST) and Alanine Transaminase (ALT)] following perinatal asphyxia and its correlation with respect to mortality among the neonates with Hypoxic ischemic encephalopathy.

\section{Materials and Methods}

This is a prospective case control study. A total of 210 term neonates were enrolled in the study which included 2 groups- 158 neonates with HIE (cases) and 52 normal neonates as controls, admitted to Neonatal Intensive care unit of Vanivilas Children Hospital and Bowring and Lady Curzon hospital attached to Bangalore Medical College \& Research Institute during 2010 \& 2011. Cases were being the neonates who had perinatal asphyxial insult. i. e. neonates requiring positive pressure ventilation before the onset of stable spontaneous respiration with Apgar score of less than 3 at 5 minutes of lifeand control group included the normal healthy neonates who were delivered in the hospital with any kind of morbidities. Special consent was taken from parents of control group for the purpose of study.

Outborn babies who reached hospital after 12 hours of birth were excluded. We compared the dynamics of serum lactate dehydrogenase (LDH), Aspartate transaminase (AST) and Alanine transaminase (ALT) between cases and controls and studied their outcome.
After taking the informed written consent from the parent or guardian, the relevant information from the history, physical examination was recorded in a predesigned proforma. Maternal characteristics recorded included age, parity, gestational age, antenatal risk factors, mode of presentation and delivery. Also natal risk factors, mode of resuscitation, Apgar score and time of onset of spontaneous breathing were collected. Babies were examined soon after birth and preliminary data regarding the babies were collected.

Hypoxic Ischemic encephalopathy staging was done according to Sarnat and Sarnat staging system [23], in which HIE stage I - babies were irritable, hyperalert, jittery with normal/increased tone, regular respiratory pattern, with no seizures and normal EEG (electroencephalogram) pattern. In HIE stage II, neonates are noticed to be lethargic, hypotonic, with a periodic respiratory pattern, decreased reflexes, with frequent seizures and an abnormal EEG pattern (low voltage complexes with seizure activity). In HIE stage III, neonates are comatose, flaccid/severely hypotonic, prolonged, frequent and difficult to treat seizures with severely abnormal EEG pattern (burst suppression pattern to isoelectric pattern). Due to the nonavailability of bed side continuous EEG, we did not consider EEG in diagnosing the HIE and classifying the stages of HIE. Venous blood sample collected at less than 12 hours of birth and at 72 hours after the birth for estimation of serum LDH, AST and ALT and analyzed in the same laboratory attached to both the hospitals. Enzyme analysis was done using colorimetric assay according to IFCC in COBAS Integra 400 of Roche diagnostic [24, 25]. Reference range for the enzymes are as follows: for $\mathrm{LDH}$ above $580 \mathrm{U} / \mathrm{L}$, ALT above $140 \mathrm{U} / \mathrm{L}$, AST above $50 \mathrm{U} / \mathrm{L}$ and ALP above 319U/L are considered abnormal and high [26]. Routine screening for Inborn errors of metabolism was not done. These babies were monitored for complications and later followed up till completed 2 months of age, and data regarding morbidity and mortality were also documented.

Ethical clearance was obtained through Institution's Ethical Committee and review board. (ERB)

\section{Inclusion Criteria}

- Apgar score of less than 3 at 5 minutes of birth.

- Gestational age between 37 to 42 weeks.

- Resuscitation with positive pressure ventilation before the onset of stable spontaneous respiration. 


\section{Exclusion Criteria}

- Preterm neonates (<37 Completed weeks).

- Neonates with suspected sepsis (septic screen positivity) and proven sepsis (blood culture positivity).

- Neonates receiving potentially hepatotoxic drugs (Ampicillin, Gentamicin, Isoniazid, Rifampicin).

- Neonates with major congenital malformations (Neural tube defects, GI tract anomalies, genito-urinary anomalies, complex congenital heart diseases) and chromosomal anomalies.

- Neonates born to mothers who have received opioids or magnesium sulphate.

- Neonates with suspected and proven metabolic disorders.
- Neonates who are born to mothers with proven infective hepatitis (HBsAg positivity and/or Anti HAV positive)

Statistical Analysis: Descriptive statistical analysis carried out in the present study. Analysis of variance (ANOVA) is used to find the significance of study parameters between three or more groups of patients. Student $t$ test (two tailed, independent) has been used to find the significance of study parameters on continuous scale between two groups on metric parameters, Chisquare/ Fisher Exact test were used to find the significance of study parameters on categorical scale between two or more groups. The Statistical software namely SPSS 15.0, Stata 8.0 and Systat 11.0 were used for the analysis of the data.

\section{Results}

Samples are matched for age and parity of mothers; gender, weight of the neonates (though LBW neonates were more in the asphyxia group) and their modes of presentation at delivery. The mean gestational age in cases was $39.04 \pm 0.6$ weeks and in the control group was $38.44 \pm 0.4$ weeks and is of no statistic significance. The mean birth weight of neonates among the cases was $2.68 \pm 0.26 \mathrm{~kg}$ as compared to $2.90 \pm 0.30 \mathrm{~kg}$ in the control group, which was statistically insignificant. Several risk factors which can cause perinatal asphyxia were studied both in neonates and mothers, of which the following were significant : Pregnancy induced hypertension ( $p$ value of 0.013 ), cord around the neck ( $p$ value of $<0.001$ ), prolonged 2nd stage of labour ( $p$ value of $<0.001$ ) and Meconium stained amniotic fluid( $p$ value 0.01 ), other risk factors which were studied include Antepartum hemorrhage and severe anemia in the mother which were not statistically significant.

Apgar scores were documented and 45.6\% of HIE neonates had a low Apgar of less than 5 at 10 minutes \& $2.5 \%$ had a score of less than 5 at 20 minutes. $73.4 \%$ had onset of spontaneous breathing at $5-10$ minutes of life \& $24.1 \%$ after 10 minutes of birth. The mean Apgar score at 10 and 20 minutes in HIE stage III being $5.21 \pm 1.22$ and $7.38 \pm 1.21$ which is significantly less than HIE stage I and II. Hypoxic hepatitis occurrence was seen in $62.65 \%$ of total neonates with HIE. Among the different grades of HIE, 22 of 24 HIE stage III neonates; 56 of 79 HIE stage II neonates and 9 of the 55 neonates with HIE stage I had evidence of hypoxic hepatitis.

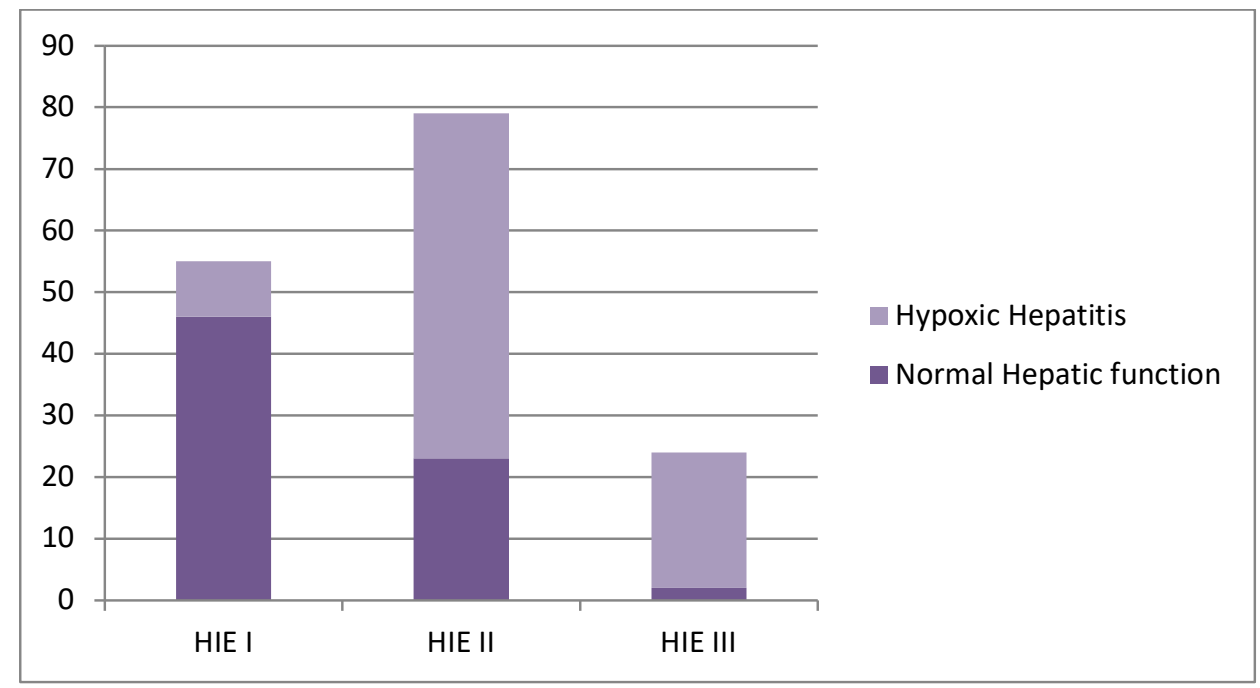

Figure-I: Hypoxic Hepatitis among the different stages of HIE 
Mean enzyme levels of LDH, AST and ALT were significantly higher among cases in comparison with the controls at 12 hrs and on day 3 of life as shown in table I and depicted in figure II.

Table-I: Comparison of Mean levels of enzymes in sample of neonates studied.

\begin{tabular}{|c|c|c|c|}
\hline & $\begin{array}{c}\text { LDH } \\
\text { Mean } \pm \text { S.D }\end{array}$ & $\begin{array}{c}\text { AST } \\
\text { Mean } \pm \text { S.D }\end{array}$ & $\begin{array}{c}\text { ALT } \\
\text { Mean } \pm \text { S.D }\end{array}$ \\
\hline Cases-Day1 & $958.81 \pm 493.37$ & $123.34 \pm 103.39$ & $111.08 \pm 174.92$ \\
\hline Control-Day1 & $383.90 \pm 134.77$ & $46.12 \pm 21.42$ & $29.85 \pm 9.31$ \\
\hline Cases-Day 3 & $981.20 \pm 740.88$ & $117.60 \pm 97.12$ & $99.29 \pm 98.14$ \\
\hline Control-Day3 & $372.00 \pm 126.46$ & $38.35 \pm 18.15$ & $25.76 \pm 9.51$ \\
\hline
\end{tabular}

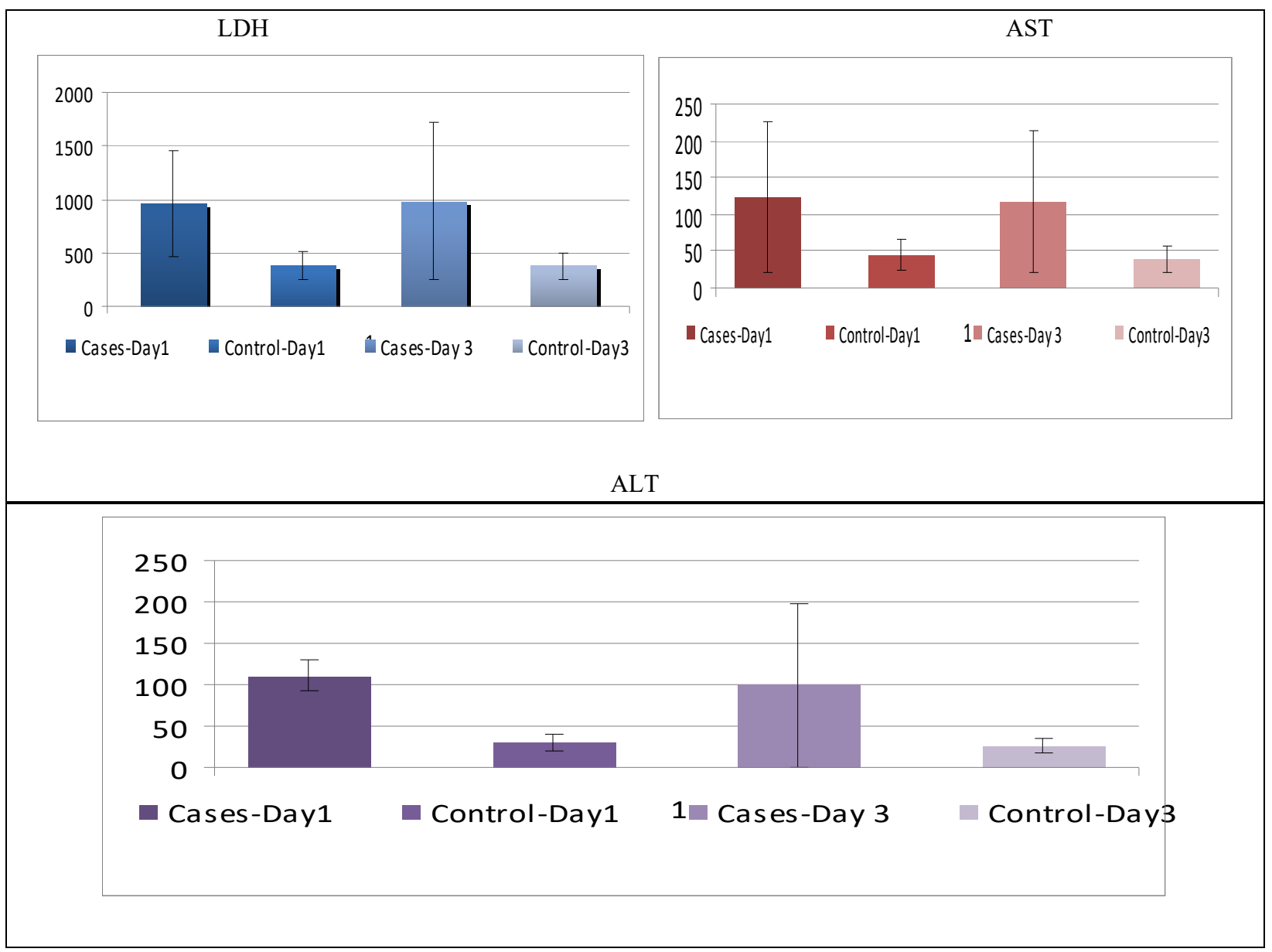

Figure-II: Comparison of Mean levels of enzymes in sample of neonates studied

Table-II: Comparison of status of Liver function in expired and survived neonates with HIE

\begin{tabular}{|c|c|c|}
\hline & Deranged liver function & Normal Liver function \\
\hline Expired & $9(90 \%)$ & $1(10 \%)$ \\
\hline Survived & $89(60.1 \%)$ & $59(39.9 \%)$ \\
\hline Total & $98(62.65 \%)$ & $60(37.35 \%)$ \\
\hline Inference & Deranged liver function is significantly more associated with expired cases \\
& \multicolumn{2}{|c|}{ with $\mathrm{p}<0.001 * *$} \\
\hline
\end{tabular}


Of the 158 neonates in the study group with HIE, 28 of them expired, but mortality due to Hypoxic ischemic encephalopathy per se being 10. Remaining 18 neonates died due to following causes: 10 of them due to severe meconium aspiration syndrome, 5 due to severe persistent primary pulmonary hypertension and 3 due to pneumothorax. The neonates who were discharged (cases) were followed up in the neonatal neuro-developmental follow up clinic at 2 months of post natal age. Out of 158 neonates (cases) included in the study group, 31 neonates were excluded (as 28 neonates expired and 3 lost for follow up), among the remaining neonates, $25.9 \%$ had neurological sequelae like tone abnormalities and seizures. We compared the status of hepatic dysfunction in expired and surviving neonates which revealed that $90 \%$ of the expired neonates had deranged liver functions as compared to $10 \%$ of neonates with normal enzyme levels with a significant $\mathrm{p}$ value of $<0.001$ as shown in table II.

Mean enzymes levels studied on day1 and day 3 of life show significantly higher values in non survivors than the survivors with ALT being most specific (100\% specificity). Among the three enzymes studied, LDH has the highest sensitivity $(96.15 \%)$ in the present study.

Table-III: Mean levels of enzymes in survivors and non-survivors on Day 1.

\begin{tabular}{|c|c|c|c|}
\hline Day 1 & $\begin{array}{c}\text { Survivors } \\
\text { Mean } \pm \text { S.D }\end{array}$ & $\begin{array}{c}\text { Non-Survivors } \\
\text { (HIE related) } \\
\text { Mean } \pm \text { S.D }\end{array}$ & P value \\
\hline LDH & $881.61 \pm 441.52$ & $1302.24 \pm 569.23$ & $<0.001^{* *}$ \\
\hline AST & $109.92 \pm 95.75$ & $183.03 \pm 116.97$ & $<0.001^{* *}$ \\
\hline ALT & $82.54 \pm 90.98$ & $238.07 \pm 336.55$ & $<0.001^{* *}$ \\
\hline
\end{tabular}

Table-IV: Mean levels of enzymes in survivors and non-survivors on Day 3.

\begin{tabular}{|c|c|c|c|}
\hline Day 3 & $\begin{array}{c}\text { Survivors } \\
\text { Mean } \pm \text { S.D }\end{array}$ & $\begin{array}{c}\text { Non-Survivors } \\
\text { (HIE related) } \\
\text { Mean } \pm \text { S.D }\end{array}$ & P value \\
\hline LDH & $841.73 \pm 445.58$ & $1647.56 \pm 1318.07$ & $<0.001^{* *}$ \\
\hline AST & $96.57 \pm 84.43$ & $218.07 \pm 91.99$ & $<0.001^{* *}$ \\
\hline ALT & $76.67 \pm 84.29$ & $207.33 \pm 88.26$ & $<0.001^{* *}$ \\
\hline
\end{tabular}

\section{Discussion}

Severe birth asphyxia frequently induces multiorgan failure with cardiovascular, renal, cerebral and hepatic damage. The circulation of the liver is unique with its dual supply of blood flow arising from both the hepatic artery and the portal vein. The liver accounts for $20 \%$ of the total fetal oxygen consumption. In the human fetus, the liver receives approximately $80 \%$ of all the blood from the umbilical vein while $20 \%$ is shunted through the ductus venosus. Leakage of intracellular enzymes such as aspartate aminotransferase (AST), alanine aminotransferase (ALT) and lactate dehydrogenase (LDH) signaling multiorgan dysfunction (MOD) is seen together with hypoxic ischemic encephalopathy (HIE) after perinatal asphyxia, hence they may be used as potential predictors of timing and grade of the hypoxic ischemic injury in both the perinatal period and in infants with antepartum asphyxia. Hypoxic hepatitis is an early, sharp and transient increase in amino- transferases (ALT and AST) and LDH plasma activity seen after an acute cardiac or circulatory failure in the absence of viral hepatitis. The time course of enzyme activity pattern in hypoxic hepatitis begins with a slightly increased serum AST and/ or serum ALT close to the triggering event, followed by a peak concentration of aminotransferases and LDH in serum within 24 to $72 \mathrm{hrs}$ after the insult. After the peak, aminotransferases levels return to near normal within ten days. A biochemical parameter that correlates with HIE is of interest, since artificial ventilation, sedative drugs and anticonvulsant drugs could make the evaluation of the severity of neonatal encephalopathy difficult $[6,7,8]$.

In this study, hepatic involvement in neonates with HIE studied is $62.65 \%$, which in comparison is similar to studies done by Karlsson et al [12] and Saili et al [14] 
which showed $64.52 \%$ and $65.38 \%$ respectively. Studies done by Gary Hankins et al [18] and Shah et al [8] showed a higher occurrence of $80 \%$ and $84.6 \%$ which could be explained due to single measurement of enzymes during the first week of life. Recent studies done by Mukesh $\mathrm{C}$ et al [21], incidence of HIE was $42.85 \%$ which was lower comparatively and by Nanda $\mathrm{C}$ et al [22], hypoxic hepatitis was seen in $56 \%$ of the asphyxiated neonates.

Mortality was significantly more in the neonates with HIE with deranged liver function about $28.8 \%$ whereas $1.6 \%$ with normal liver function with a significant $\mathrm{P}$ value of $<0.001$ in the present study. Similar observations were seen in study by Shah et al [8].

In this study, there was elevated enzyme levels ( $\mathrm{LDH}$, ALT, AST) in all the stages of HIE, with a highest mean enzyme levels in stage III HIE which implicated a correlation between elevation of enzyme levels \& severity of HIE. Mean Serum LDH levels at less than $12 \mathrm{hrs}$ of life among cases were $958.81 \pm 493.37$ and controls were $383.90 \pm 134.77$ in our study. In comparison, study by Karlsson et al [12], day 1 levels were $3866 \pm 4980$ and $930 \pm 254$ in cases and controls respectively. On day 3 of life, in our study, the mean Serum LDH levels were 981.20 \pm 740.88 and $372.00 \pm 126.46$ among cases and controls respectively compared to levels in Karlsson et al [12] study which was $4755 \pm 6644$ in cases and $772.9 \pm 147$ in controls. Though the study done by Karlsson et al showed similar elevation on both the days, the values were much higher comparatively. Study by Mukesh C et al [21], LDH was $455.27 \pm 305.83 \mathrm{U} / \mathrm{L}$ in cases as compared to $329.40 \pm$ $154.89 \mathrm{U} / \mathrm{L}$ in controls on day 1 . On day 3, LDH was $1205.42 \pm 655.55 \mathrm{U} / \mathrm{L}$ among the cases as compared to $322.33 \pm 122.02 \mathrm{U} / \mathrm{L}$ in controls. The elevation in mean enzyme levels were similar to our study. Nanda Chhavi et al [22] study also showed a significant difference.

Mean ALT levels at less than $12 \mathrm{hrs}$ of life among cases were $123.34 \pm 103.39$ and controls were 46.12 \pm 21.42 . On day 3 of life, the mean level was $117.60 \pm 97.12$ and $38.35 \pm 18.15$ among cases and controls respectively. Karlsson et al in their study found a similar significant difference between the two groups of neonates studied with a $p$ value of 0.002 with mean values being higher in the cases. In studies done by Sanath Reddy et al [16], Md Tariqul I et al [19]' Mukesh C et al [21], Nanda C et al [22] and Saili et al [14], there was similar statistically significant difference between cases and control neonates studied on day 3 of life. In our study, mean
AST levels at less than $12 \mathrm{hrs}$ of life among cases were $111.08 \pm 174.92$ and controls were $29.85 \pm 9.31$. On day 3 of life, the mean ALT levels were 99.29 \pm 98.14 and 25.76 \pm 9.51 among cases and controls respectively. $\mathrm{Md}$ Tariqul I et $\mathrm{al}^{19}$, Karlsson et al [12], Mukesh $\mathrm{C}$ et al [21], Nanda C et al [22] and Saili et al [14] showed a similar significant mean levels between both the groups.

There was also association between elevated enzymes $\&$ mortality where in neonates, who expired had higher significant enzyme levels compared to surviving neonates. In the present study, Serum LDH enzyme was highly sensitive $(96.1 \%)$ \& ALT being highly specific $(100 \%)$. In the present study, LDH has the highest sensitivity among the enzymes studied, which is similar to studies done by Karlsson et al [12] and Sanath Reddy et al [16] which showed a $100 \%$ sensitivity. In study by Karlsson et al [12], they also found ALT to have 100\% sensitivity.

Hence Serum LDH levels can be used to discriminate perinatal asphyxia from other illnesses more accurately than other hepatic enzymes retrospectively. This can be used in cases of diagnostic dilemma in neonates presenting with non-specific signs of HIE first 72 hours of life.

\section{Conclusion}

- Occurrence of hypoxic hepatitis in full term neonates with HIE in the present study is $62.65 \%$.

- There is significant difference between all the mean enzyme values of LDH, AST and ALT in all the three stages of HIE with stage III having a higher mean value as compared to stage II and I.

- There was significant mortality in neonates with hypoxic hepatitis. Deranged liver function was seen in $90 \%$ of expired neonates with a significant $p$ value of $<$ 0.001 .

- LDH has the highest sensitivity. ALT being the most specific of the 3 enzymes studied with also the highest positive predictive value.

- LDH and aminotransferases (ALT and AST) levels showed a statistically significant correlation with the severity and mortality due to HIE.

\section{Limitations of The Study}

- Serial enzyme levels until normalized could not be done due to difficulty in obtaining further blood samples.

- LDH isoenzyme 5 which is specific for liver was not assessed. 
- Routine screening for inborn errors of metabolism (for both cases and controls)was not done.

- Long term neurological assessment and follow up and assessment could not be done in the present study.

Funding: Nil, Conflict of interest: Nil Permission from IRB: Yes

Acknowledgement: We, Authors would like to thank Prof Dharmapuri Vidyasagar for reviewing the article.

\section{Each Authors contributions:}

Author 1: Principal Investigator: Designing the study, collection of the data and statistical analysis. Author 2: Co investigator: Analysis of the data and writing of manuscript.

Author 3: Co investigator: Monitored and Guided the study. Author 4: Co investigator: Laboratory data analysis and clinical correlation.

\section{Bibliography}

1. Lawn JE, Cousens S, Zupan J; Lancet Neonatal Survival Steering Team. 4 million neonatal deaths: when? Where? Why? Lancet. 2005 Mar 5-11;365 (9462):891-900

2. Saving Newborn Lives. The state of the world's newborn:a report from saving newborn lives. Washington DC, Save the children: 2001; 1-44.

3. Lawn J, Shibuya K, Stein C. No cry at birth: Global estimates of intrapartum stillbirths and intrapartumrelated neonatal deaths. Bulletin of World Health Organization. 2005 Jun 17;83(6):409-17. Epub 2005 Jun 17.

4. Report of the National Neonatal Perinatal Database (National Neonatology Forum, India) 2000.

5. Jensen A, Garnier Y, Berger R. Dynamics of fetal circulatory responses to hypoxia and asphyxia.European journal of Obstetrics, Gynaecology and Reproductive Biology. 1999;84:155-172.

6. Hankins GD, Koen S, Gei AF, Lopez SM, Van Hook JW, Anderson GD. Neonatal organ system injury in acute birth asphyxia sufficient to result in neonatal encephalopathy. Obstet Gynecol. 2002 May;99 (5Pt 1) : 688-91.

7. Martín-Ancel A, García-Alix A, Gayá F, Cabañas F, Burgueros M, Quero J. Multiple organ involvement in perinatal asphyxia. J Pediatr. 1995 Nov;127(5):786-93.
8. Shah P, Riphagen S, Beyene J, Perlman M. Multiorgan dysfunction in infants with post-asphyxial hypoxic-ischaemic encephalopathy. Arch Dis Child Fetal Neonatal Ed. 2004 Mar;89(2):F152-5.

9. Seeto RK, Fenn B, Rockey DC. Ischemic hepatitis: clinical presentation and pathogenesis. Am J Med. 2000 Aug 1;109(2):109-13.

10. Rosser BG, Gores GJ. Liver cell necrosis: cellular mechanisms and clinical implications. Gastroenterology. 1995 Jan;108(1):252-75.

11. Reichling JJ, Kaplan MM. Clinical use of serum enzymes in liver disease. Dig Dis Sci. 1988 Dec; 33 (12):1601-14.

12. Karlsson M, Blennow M, Nemeth A, Winbladh B. Dynamics of hepatic enzyme activity following birth asphyxia. Acta Paediatr. 2006 Nov;95(11):1405-11.

13. Tarcan A, Tiker F, Güvenir H, Gürakan B. Hepatic involvement in perinatal asphyxia. J Matern Fetal Neonatal Med. 2007 May;20(5):407-10.

14. Saili A, Sarna MS, Gathwala G, Kumari S, Dutta AK. Liver dysfunction in severe birth asphyxia. Indian Pediatr. 1990 Dec;27(12):1291-4.

15. Esqué-Ruiz MT, Figueras-Aloy J, Salvia-Roigés MD, Carbonell-Estrany X. [Blood ammonia and transaminases in full term infants suffering from perinatal asphyxia]. Rev Neurol. 2003 May 1-15;36 (9):801-5.

16. Sanath R, Sourabh D, Anil N. Evaluation of lactate dehydrogenase, creatine kinase and hepatic enzymes for the retrospective diagnosis of perinatal asphyxia among sick neonates. Indian Pediatrics 2008 February 17; 45: 144-147.

17. Godambe SV, Udani RH, Malik S, Kandalkar BM. Hepatic profile in asphyxia neonatorum. Indian Pediatr. 1997 Oct ;34(10):927-30.

18. Hankins GD, Koen S, Gei AF, Lopez SM, Van Hook JW, Anderson GD. Neonatal organ system injury in acute birth asphyxia sufficient to result in Neonatal Encephalopathy. Obstet Gynecol 2002; 99: 688-91.

19. Tariqul MI, Seikh AH, Matin M,Nazrul MI,Anwar MH, Fahmida N, Shahnoor I. Alteration of Hepatic Function: Helpful to Diagnose and Assess Severity of Perinatal Asphyxia. Bangladesh J Child Health 2010; $34(1): 8$. 
20. Zanardo V, Bondio M, Perini G, Temporin GF. Serum glutamic-oxaloacetic transaminase and glutamicpyruvic transaminase activity in premature and fullterm asphyxiated newborns.Biol Neonate1985; 47: 61-69.

21. Mukesh C, Deepak S, Dhanraj D, Mamta L, Aakash P, Sweta S. Hepatic Dysfunction in Asphyxiated Neonates: Prospective Case- Controlled Study. Clinical Medicine Insights: Pediatrics 2015; 9: 1-6. DOI: 10.4137/CMPed. S21426.Epub 2015 Jan 12.

22. Nanda C, Kiran Z, Niranjan KS, Ashish A, Amit G. Serum Liver Enzyme Pattern in Birth Asphyxia Associated Liver Injury. Pediatric Gastroenterology Hepatology and Nutrition 2014; 17(3):162-169. Epub 2014 Sep 30.
23. Sarnat HB, Sarnat MS. Neonatal encephalopathy following fetal distress. A clinical and electroencephalographic study. Arch Neurol. 1976 Oct;33 (10):696-705 .

24. Recommended methods for the determination of four enzymes in blood. Scand J Clin Lab Invest. 1974 Jun;33(4):291-306.

25. Tietz, N. W. Clinical Guide to Laboratory Tests.3rd Edi. W.B.Saunders, :Philadelphia;1995: 207.

26. Ruth MA, Fiana C.Neonatal Biochemical reference ranges. Appendix 6.Janet M. Rennie, N. R. C. Roberton's Textbook of Neonatology. $4^{\text {th }}$ ed : Churchill Livingstone; 2005:1300-1301.

\section{How to cite this article?}

Deepthi Ramu, Prashanth Madapura V, Sarala Sabapathy, Nidhi Rajendra: Study of dynamics of lactate dehydrogenase and hepatic enzymes activity following perinatal asphyxia in full term neonates.Int. J Pediatr Res. 2016;3(9):697704.doi:10.17511/ijpr.2016.i09.13. 